\title{
QUANTIFICATION OF THEOPHYLLINE IN GUINEA PIG PLASMA BY LC-MS/MS USING HYDROPHILIC INTERACTION LIQUID CHROMATOGRAPHY STATIONARY PHASE: METHOD DEVELOPMENT, VALIDATION, AND APPLICATION IN STUDY
}

\author{
KERTYS $\mathbf{M}^{1,2}$, URBANOVA A ${ }^{2,1}$, MOKRY $\mathrm{J}^{1,2}$ \\ ${ }^{1}$ Department of Pharmacology, Jessenius Faculty of Medicine in Martin, Comenius University in \\ Bratislava, Slovakia \\ ${ }^{2}$ Biomedical Center Martin, Jessenius Faculty of Medicine in Martin, Comenius University in \\ Bratislava, Slovakia
}

\begin{abstract}
Theophylline has been used in the treatment of bronchial asthma and chronic obstructive pulmonary disease (COPD) for over 70 years. In order to maximize the effectiveness and safety of theophylline therapy it is important to individualize the dosage of the drug. In our study we focused on determination of theophylline concentrations in guinea pig plasma. A rapid, specific, and reliable LC-MS/MS-based method was developed and validated according to European Medicine Agency (EMA) guidelines. A hydrophilic interaction liquid chromatography (HILIC) separation mode for reduction time of sample preparation was used. The analysed sample was quantified in a positive ionization mode. Multiple reaction monitoring (MRM) using transition $\mathrm{m} / \mathrm{z} 181.06 \rightarrow 124.06$ and $\mathrm{m} / \mathrm{z} \quad 187.17 \rightarrow 127.06$ was performed to quantify theophylline with deuterated internal standard $\left(\left[{ }^{2} \mathrm{H}_{6}\right]\right.$-theophylline), respectively. Modification of collision energies was performed in parallel with chromatographic separation to further eliminate interference from the matrix. The method was validated for a range of 0.5 to $30 \mu \mathrm{g} / \mathrm{mL}$ of plasma sample. The intra-day and inter-day precision and accuracy of the quality control samples at low, medium, and high concentration levels exhibited relative standard deviations (RSD) of less than $10 \%$. The method was successfully applied for the quantitation of theophylline in guinea pig plasma for better understanding its effects in a model of ovalbumin-induced allergic inflammation.
\end{abstract}

Key words: theophylline, HILIC, liquid chromatography, mass spectrometry, guinea pig, plasma.

\section{INTRODUCTION}

Theophylline is a xanthine derivative, pharmacologically similar to other xanthine compounds, theobromine and caffeine; however, there is a variation in the intensity of their actions (1). Theophylline is extensively metabolized in vivo and eliminated by cytochrome P-450-mediated hepatic oxidation, predominantly by 8 -hydroxylation to 1,3-dimethyluric acid. In addition, theophylline is converted to 1-methylxantine and 3-methylxantine $(2,3)$. Metabolic pathways of theophylline with structure of its metabolites are shown in Fig. 1.

Although theophylline has been used in clinical practice for a long time, some of its mechanisms of action at molecular level are still not completely elucidated. Several molecular mechanisms of action have been proposed, but they appear to occur predominantly at higher concentrations than are clinically relevant - often more than $20 \mathrm{mg} / \mathrm{L}$ (Table 1). Theophylline competitively and non-selectively inhibits phosphodiesterases which degrade

Address for correspondence:

Martin Kertys, PharmDr., Department of Pharmacology, Jessenius Faculty of Medicine in Martin, Comenius University in Bratislava, Mala Hora 4/C, 03601 Martin, Slovakia;

Phone: +421 43 2633603; e-mail: kertys@jfmed.uniba.sk 
cyclic AMP (cAMP) - the increased concentrations of intracellular cAMP mediate pharmacologic effects of the drug (4-7).

Tab. 1 Proposed mechanism of action of theophylline (11)

\begin{tabular}{|l|}
\hline Phosphodiesterase inhibition (nonselective) \\
\hline Adenosine receptor antagonism \\
\hline Increased interleukin (IL)-10 release \\
\hline Stimulation of catecholamine release \\
\hline Mediator inhibition (prostaglandins, tumor necrosis factor- $\alpha$ ) \\
\hline Inhibition of intracellular $\mathrm{Ca}^{2+}$ release \\
\hline Inhibition of nuclear factor- $\kappa \mathrm{B}(\downarrow$ nuclear translocation) \\
\hline Increased apoptosis \\
\hline$\uparrow$ Histone deacetylase activity (HDAC, $\uparrow$ efficacy of corticosteroids) \\
\hline
\end{tabular}

The therapeutic range of effective plasma concentrations of theophylline is relatively narrow and various side effect occur when plasma levels exceed $20 \mathrm{mg} / \mathrm{L}$ (8). Asthmatic patients receive a variety of dosage forms of theophylline in different dose schedules. Serum theophylline concentrations show considerable inter-individual variations in patients, presumably due to variations in the extent of metabolism. Based on recommendations of several authors the theophylline levels required for an optimal bronchodilator effect range from 8 to $20 \mathrm{mg} / \mathrm{L}(9-11)$.

In recent years several high-performance liquid chromatography (HPLC)-based analytical methods using UV detection have been proposed and published for the quantitation of theophylline. Most of these methods suffer from long run times and poor selectivity or lack of validation (12-16). In last years HPLC coupled to mass spectrometry (MS) plays an important role in drugs concentrations determination. The use of MS has decreased detection limits to $\mathrm{ng} / \mathrm{mL}$ and using ultra-high performance liquid chromatography (UHPLC) has led to a significant reduction of run times (under 10 minutes). However, many of the published methods for theophylline determination involve multistep extractions, large volumes of organic solvent, and require a complicated sample preparation $(17,18)$. A hydrophilic interaction liquid chromatography (HILIC) separation mode has emerged as a valuable complementary technique to reversed-phase (RP), being especially suitable for an analysis of polar and ionized solutes which are difficult to retain in RP. A characteristic of HILIC is the use of polar stationary phase and an eluent composed of an aqueous buffer solvent and an organic water-soluble modifier (e.g. acetonitrile). Separation of the analytes is based on their respective hydrophilicity or polarity. HILIC separations are very easy to combine with MS analysis of water-soluble polar compounds because the high organic content in the mobile phase leads to rapid evaporation of the solvent during electrospray ionization $(19,20)$. Up to now there has been no validated method for determination of theophylline in guinea pig plasma using HILIC separation mode published yet $(21,22)$. The importance lies in the fact that the effects observed in experimental study are dependent on the plasma levels $(6,7)$. These can be influenced by the dose administered, inter-species differences in the metabo- 
lism and elimination, and potential interactions when administering theophylline with other drugs in combination therapy. Therefore, the exact plasma concentrations may elucidate the effectiveness of the therapy observed during experiments (in vivo reactivity, in vitro reactivity, anti-inflammatory action, etc.), adverse effects observed especially in cardiovascular system, as well as the risk of pharmacokinetic interactions during administration (15). Furthermore, the method can be used in other species in order to compare the metabolism and effectiveness of theophylline in various experimental conditions (e.g. meconium aspiration syndrome, acute lung injury, etc.; 23-25).

The aim of our study was to develop and validate an LC-MS/MS method (using European Medicine Agency - EMA parameters) for determination of theophylline concentrations in guinea pig plasma and to apply this method for a measurement of theophylline concentrations required for subsequent correlations with airway reactivity in ovalbumin-induced allergic inflammation $(26,27)$. We focused on reducing the duration of sample preparation and run time of analysis. Our method was fully validated and suitable for a routine analysis.

\section{MATERIAL AND METHODS}

\section{Chemicals and Reagents}

Theophylline, $\left[{ }^{2} \mathrm{H}_{6}\right]$-theophylline solution (100 $\mathrm{gg} / \mathrm{mL}$ in methanol), LC/MS grade methanol, LC/MS grade acetonitrile, LC/MS grade water for chromatography and formic acid 98-100 \% for LC/MS were purchased from Sigma-Aldrich (St. Louis, MO, USA). K EDTA $_{3}$ guinea pig plasma was purchased form Innovative Research (Novi, MI, USA). Ovalbumin (lyophilized powder, > 98\%) and other reagents used in this study were of analytical grade and were purchased from Sigma-Aldrich (St. Louis, MO, USA).

\section{Mass Spectrometry}

A Waters (Waters, Prague, CZ) Xevo TQ-S triple quadrupole mass spectrometer was used. Mass spectra were acquired using positive electrospray ionization and MRM transitions. The capillary voltage was $3.0 \mathrm{kV}$ and the source temperature and desolvation temperature were 150 and $550{ }^{\circ} \mathrm{C}$, respectively. The cone gas and desolvation gas flowed at 150 and $1000 \mathrm{~L} / \mathrm{h}$, respectively. As a collision gas we used argon flowed at $0.15 \mathrm{~mL} / \mathrm{min}$. The collision energies and source cone voltages were manually optimized for each MRM transition. Data were acquired with MassLynx 4.1(Waters, Prague, CZ) and quantified by TargetLynx software (Waters, Prague, CZ).

\section{Ultra-Performance Liquid Chromatography}

We used Waters ACQUITY UPLC (Waters, Prague, CZ) system (consisting of an autosampler, a binary LC pump (BSM) and column oven), and CORTECS UPLC HILIC column - $2.1 \mathrm{~mm}$ x $50 \mathrm{~mm}, 1.6 \mu \mathrm{m}$ particle size (Waters, Prague, CZ) with HILIC VanGuard pre-column (Waters, Prague, CZ) for analyses. Mobile phase A consisted of $0.1 \%$ formic acid in water, and mobile phase B was pure acetonitrile. Mobile phase gradient program was as follows: $2.5 \%$ of A for $0.1 \mathrm{~min}$; increased to $6 \% \mathrm{~A}$ from 0.1 to $0.5 \mathrm{~min} ; 20 \% \mathrm{~A}$ from $0.5 \mathrm{~min}$ to $1.4 \mathrm{~min} ; 20 \% \mathrm{~A}$ from 1.4 to 1.5 , and then $2.5 \% \mathrm{~A}$ from $1.5 \mathrm{~min}$ to $3.2 \mathrm{~min}$. Column temperature was set at $30{ }^{\circ} \mathrm{C}$. The flow rate was $0.4 \mathrm{~mL} / \mathrm{min}$ and injection volume was $0.125 \mu \mathrm{L}$. The auto-sampler temperature was set at $8{ }^{\circ} \mathrm{C}$.

\section{Standard Stock Solution and Working Solution Preparation}

Standard stock solution containing $1 \mathrm{mg} / \mathrm{mL}$ concentration of theophylline and $10 \mu \mathrm{g} / \mathrm{mL}$ of $\left[{ }^{2} \mathrm{H}_{6}\right]$-theophylline (internal standard solution - IS) were made up in methanol. Stock solutions were stored at $-80^{\circ} \mathrm{C}$. Working solutions of six standards $(0.5,1,3,10,20$ and $30 \mu \mathrm{g} / \mathrm{mL}$ ) and three quality control samples $(\mathrm{QCs}, 0.5,10.0$, and $22.0 \mu \mathrm{g} / \mathrm{mL}$ ) were pre- 
pared in $1 \mathrm{~mL}$ drug-free guinea pig plasma by dilution of the stock solution. The standards were prepared on the day of analysis, and the QCs were prepared in bulk monthly and stored at $-80^{\circ} \mathrm{C}$. The sample preparation started with a protein precipitation step. The $50 \mu \mathrm{L}$ of plasma and $5 \mu \mathrm{L}$ of IS solution $(10 \mu \mathrm{g} / \mathrm{mL})$ were vortexed rigorously for 20 seconds, followed by an addition of $1.5 \mathrm{ml}$ of pure acetonitrile. The mixture was consequently vortexed for 45 seconds and then centrifuged at $16500 \mathrm{x}$ g for $5 \mathrm{~min}$ at $4{ }^{\circ} \mathrm{C}$. Supernatant was transferred to sample vials and analysed by UPLC-MS/MS.

\section{Method Validation}

The method was validated according to the European Medicine Agency (EMA) guidelines with respect to selectivity, linearity, accuracy, precision, recovery, matrix effect, and stability.

\section{Selectivity and lower limit of quantification}

To investigate the method selectivity, six guinea pig plasma blank samples were pre-treated and analysed at lower limit of quantification (LLOQ).

\section{Calibration curve}

A calibration curve was constructed from a blank sample (blank plasma processed without an IS), a zero sample (plasma processed with IS), and six non-zero samples covering the total range $0.5-30.0 \mu \mathrm{g} / \mathrm{mL}$. Six samples of each concentration were measured and the curves were fitted by a linear weighted $\left(1 / \mathrm{x}^{2}\right)$ least squares regression method through the measurement of peak-area ratio of analyte to IS. The calibration curve had to have a correlation coefficient $\left(\mathrm{r}^{2}\right)$ of 0.98 or higher. The acceptance criterion for each back calculated standard concentration was $15 \%$ deviation from the nominal value except LLOQ which was set at $20 \%$.

\section{Recovery}

Recovery of theophylline was evaluated by comparing the mean peak areas of quality control samples $(\mathrm{n}=6)$ extracted low $(0.5 \mu \mathrm{g} / \mathrm{mL})$, medium $(10.0 \mu \mathrm{g} / \mathrm{mL})$, and high $(22.0$ $\mu \mathrm{g} / \mathrm{mL}$ ) concentration levels compared with reference solutions (unprocessed). Recovery of IS was evaluated by comparing between blank spiked with IS $(n=6)$ versus reference solutions (unprocessed) of the same concentration.

\section{Matrix effects}

The matrix effects (MEs) were determined based on Matuszewski et al. (28) whether the potential ion suppression or enhancement owing to the co-eluting matrix components existed in the present experiment. The corresponding peak areas of theophylline form spikeafter-extraction samples at one concentration level $(10.0 \mu \mathrm{g} / \mathrm{mL})$ were compared in respective unprocessed or aqueous standard. MEs of IS were investigated at the concentration level of $1.0 \mu \mathrm{g} / \mathrm{mL}$ in a similar way.

\section{Precision and accuracy}

To evaluate the precision and accuracy of theophylline quantification method, QC samples at three concentration levels $(0.5,10.0$, and $22.0 \mu \mathrm{g} / \mathrm{mL})$ were analysed in six replicates. The whole experiment was reproduced for accuracy checking in three consecutive days. The method precision was calculated by using relative standard deviation (RSD \%) method and accuracy was expressed as relative error (RE \%).

\section{Stability}

Stability of stock solutions and working solutions of theophylline and IS, which were stored at $4{ }^{\circ} \mathrm{C}$ for 14 days and at room temperature $\left(21^{\circ} \mathrm{C}\right)$ for $5 \mathrm{~h}$, were tested by com- 
paring the instrument response with that of freshly prepared solutions. The analytes were considered stable when the intensities ranged between 85 and $115 \%$ of the initial solutions. The stability of theophylline in guinea pig plasma was evaluated by analysing the replicates $(n=6)$ of plasma samples that were exposed to different conditions (time and temperature) at two concentrations $(10.0$, and $22.0 \mu \mathrm{g} / \mathrm{mL}$ ). These results were compared with the results obtained from freshly prepared plasma samples. The analyte was considered to be stable in the biological matrix and acceptance criteria was $\pm 15 \%$. The long term stability was determined after exposure of the spiked samples at $-20^{\circ} \mathrm{C}$ for 30 days. The freeze-thaw stability was evaluated after complete three freeze thaw cycles.

\section{Application of the Method}

The method was applied to samples obtained from the guinea pigs. The study protocol was approved by a local Ethics Committee of the Jessenius Faculty of Medicine in Martin, Comenius University in Bratislava (Slovakia). Male adult guinea pigs of TRIK-strain, weighing 250-350 g, purchased from the Department of Experimental Pharmacology of the Slovak Academy of Sciences in Dobra Voda (Slovakia), were used in the study. The guinea pigs were kept in an animal house and had adequate food and water ad libitum. The animals were randomly divided into six groups ( $n=8$ in each). One of the groups was left without sensitization and served as a control group. The remaining five groups were sensitized with ovalbumin (OVA) for the investigation of airway responsiveness in response to repeated exposures to OVA antigen. The guinea pigs in one of the sensitized groups were given vehicle only and served as an OVA-sensitized control group. The remaining four sensitized groups were treated with theophylline at the doses of 5, 10, or $20 \mathrm{mg} / \mathrm{kg}$, given intraperitoneally for one day (single dose) or for seven days (seven doses) from the $15^{\text {th }}$ day of sensitization. Detailed information about sensitization procedure can be found in our previous publication (29). Samples of blood were taken to the $\mathrm{K}_{2}$ EDTA tubes immediately after sacrificing the animals. The blood was centrifuged immediately at $2,000 \mathrm{x}$ g for $15 \mathrm{~min}$. Afterwards, plasma was separated and kept frozen at $-80^{\circ} \mathrm{C}$ until analysis.

\section{RESULTS AND DISCUSSION}

\section{UPLC-MS/MS Method Development}

We used electrospray ionisation MS/MS to perform an analysis of theophylline concentrations. Positive ionisation was selected to quantify the analyte because positive ion mass spectrometry gave a protonated molecular ion without adduct formation over negative ionisation. The combination of chromatographic separation by UPLC and successive mass filtrations by monitoring the transition of protonated ion to product ion provided excellent specificity for the theophylline and IS. The positive ion electro-spray mass spectrum of analyte gave a protonated molecular ions at $\mathrm{m} / \mathrm{z} 181.06$ for theophylline, $\mathrm{m} / \mathrm{z} 187.17$ for IS and product ions at $\mathrm{m} / \mathrm{z} 124.06$ (theophylline quantification ion), m/z 96.08 (theophylline qualification ion), and $\mathrm{m} / \mathrm{z} 127.06$ (IS). The MRM parameters were optimized to maximize the response for analyte. This method is robust, simple, and rapid, which makes it an attractive procedure in high-throughput bioanalysis.

The CORTECS UPLC HILIC column with UPLC HILIC VanGuard pre-column was used for analysis. For the optimal separation the gradient elution program was established, using formic acid as an additive into A mobile phase for better ionisation process. Using HILIC method we reduced the time during sample preparation because high percentage of organic solvents is compatible with this type of stationary phase and led to increased signal from MS detector. The retention time for theophylline was 0.59 min (Fig. 1). The developed method used very fast separation which determined it for routine analysis. 


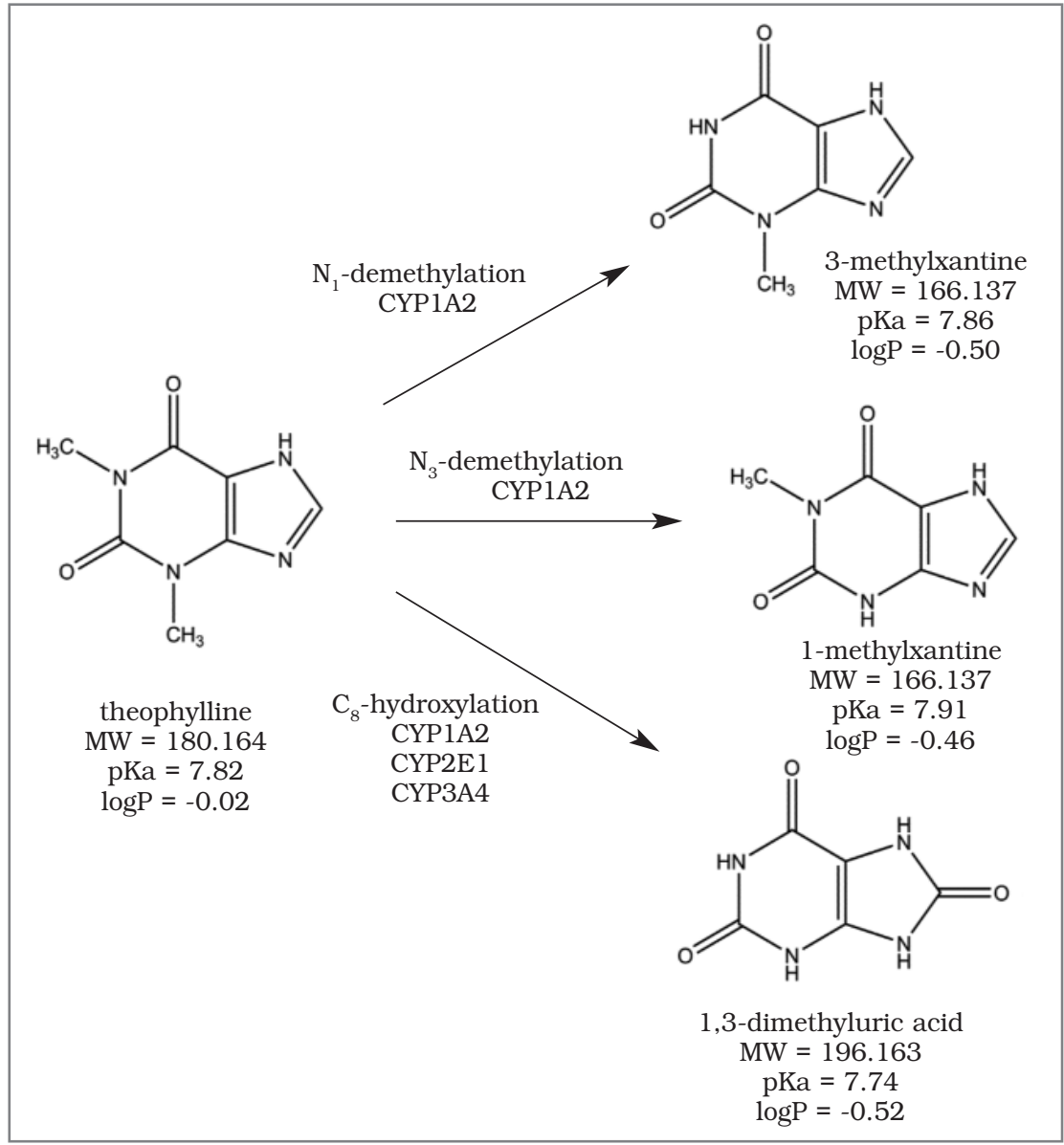

Fig. 1 Metabolic pathways of theophylline (chemical structure of theophylline and its metabolites with chemical properties).

\section{Calibration Curves}

Calibration curve was linear over the concentration range of $0.5-30.0 \mu \mathrm{g} / \mathrm{mL}$ for the analyte. The six-point calibration curve gave acceptable results for the analyte and was used for all calculations. The mean correlation coefficient of weighted $\left(1 / \mathrm{x}^{2}\right)$ calibration curve generated during the validation was 0.995 for the analyte (Fig. 3). The precision and accuracy for analyte covering the concentration of $0.5-30.0 \mu \mathrm{g} / \mathrm{mL}$ ranged from 2.12 to 8.76 and 91.23 to $106.76 \%$, respectively. The calibration curve obtained as described above was suitable for obtaining the values of the analyte concentrations in the samples during the validation for theophylline in guinea pig plasma.

\section{Specificity}

The method specificity was examined by analysing blank guinea pig plasma extract which was spiked with IS. We did not observe any significant interference from endogenous substances in the drug free plasma at the retention time of theophylline (Fig. 2). With injection volume of only $0.125 \mu \mathrm{L}$ we kept an excellent sensitivity corresponding to the whole range of calibration curve.

\section{Recovery and Matrix Effect}

The extraction recovery of theophylline was $79.2 \%$ and the recovery of $\left[{ }^{2} \mathrm{H}_{6}\right]$-theophylline was $72.1 \%$ at the concentration used in the method $(1.0 \mu \mathrm{g} / \mathrm{mL})$. Recovery of the analyte 


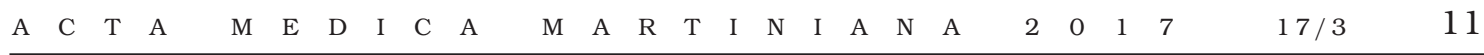

Fig. 2 LC-MRM ion-chromatograms resulting from the analysis of blank (theophylline and $\left[{ }^{2} \mathrm{H}_{6}\right]$-theophylline free) guinea pig plasma A. MRM for theophylline; B. MRM transition for $\left[{ }^{2} \mathrm{H}_{6}\right]$-theophylline and representative ionchromatograms of real sample spiked with internal standard C. MRM transition for theophylline; D. MRM transition for $\left[{ }^{2} \mathrm{H}_{6}\right]$-theophylline. Plot of signal (relative abundance, $y$-axis) versus retention time (minutes, $\mathrm{x}$-axis)

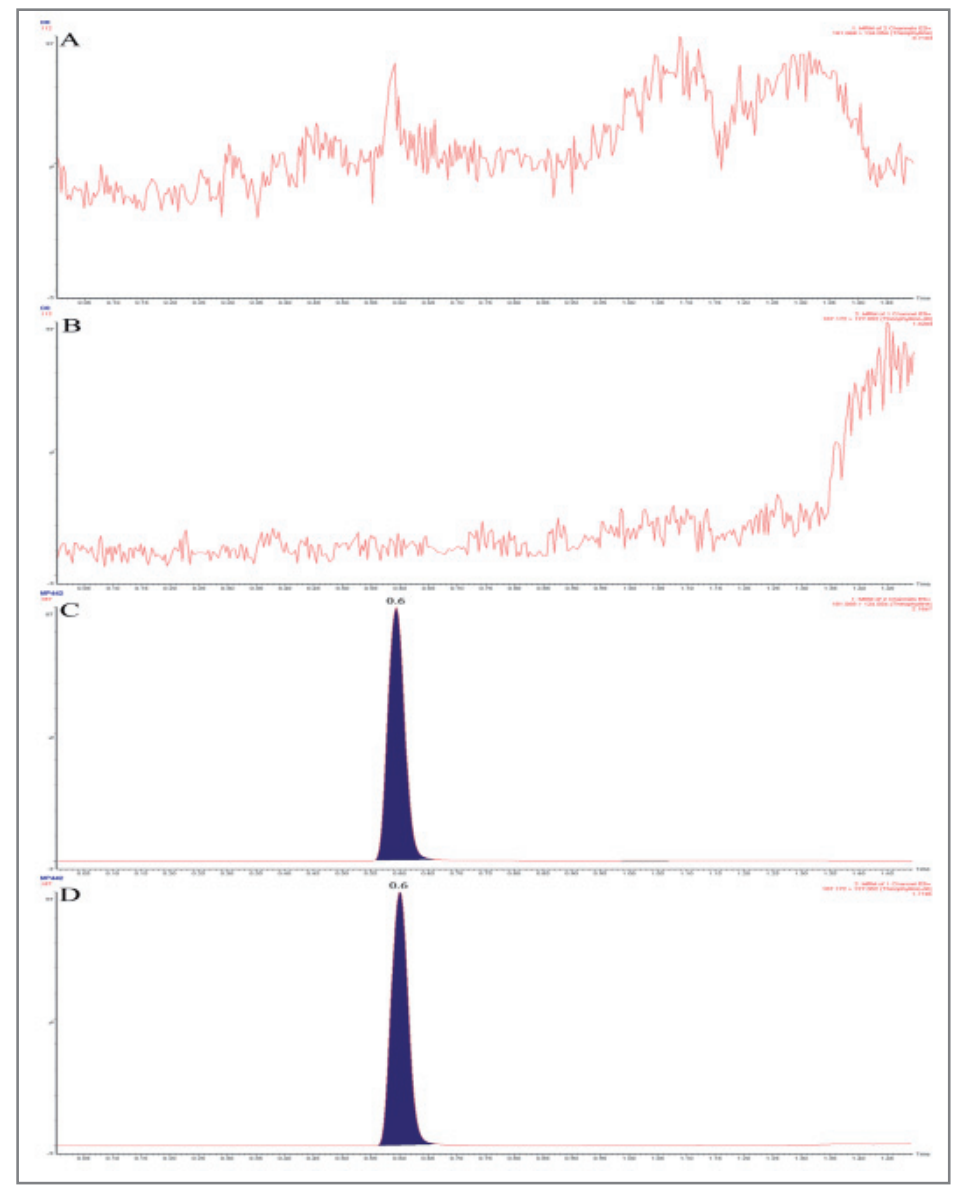

and IS were consistent, precise, and reproducible. The matrix effect was less than $10 \%$ for both analytes (2.3-8.7\%).

\section{Precision and accuracy}

The intra-day and inter-day results across three concentration levels $(0.5,10.0$, and $22.0 \mu \mathrm{g} / \mathrm{mL}$ ) for theophylline and IS ranged from 1.2-9.6\% (RSD \%) and the intra and inter-day accuracy was within 88.3-109.4 \% (RE \%).

\section{Stability}

The sample long term storage stability at $-20{ }^{\circ} \mathrm{C}$ was evaluated to establish acceptable storage conditions. Aliquots of guinea pig plasma samples spiked with theophylline at concentrations of 10.0 and $22.0 \mu \mathrm{g} / \mathrm{mL}$ were analysed on day 1 . The same samples were afterwards analysed after 30 days. The precision and accuracy for the analyte on day 30 ranged from 3.4 to 5.6 and 94.5 to $106.4 \%$, respectively. Freeze-thaw stability of the theophylline was determined by measuring the method precision and accuracy for samples which underwent three freeze-thaw cycles. The stability data were used to support repeat analysis. The frozen plasma samples containing the analyte were thawed at room temperature for 2-3 $\mathrm{h}$, refrozen for 12-24 h, repeated this cycle three times and then analysed. The results of measurement showed that theophylline was stable in guinea pig plasma through three freeze-thaw cycles. The precision ranged from 2.5 to $4.7 \%$ and the accuracy ranged from 94.7 to $101.8 \%$. 


\section{Analysis of samples}

The developed method was used for analysis of plasma samples from guinea pigs treated with different dosing schedules (one or seven times with $5 \mathrm{mg} / \mathrm{kg}, 10 \mathrm{mg} / \mathrm{kg}, 15 \mathrm{mg} / \mathrm{kg}$, or $20 \mathrm{mg} / \mathrm{kg}$ ). In groups treated with theophylline one or seven times at dose of $5 \mathrm{mg} / \mathrm{kg}$ we detected $9.5 \pm 2.6 \mu \mathrm{g} / \mathrm{mL}$ and $7.3 \pm 2.9 \mu \mathrm{g} / \mathrm{mL}$, respectively. In groups treated with one or seven doses of $10 \mathrm{mg}$ theophylline per $\mathrm{kg}$ the concentrations were $8.5 \pm 1.1 \mu \mathrm{g} / \mathrm{mL}$ and $12.1 \pm 1.1 \mu \mathrm{g} / \mathrm{mL}$, respectively. In groups of guinea pigs, which received $15 \mathrm{mg} / \mathrm{kg}$ one or seven times, the concentrations were $20.6 \pm 5.5 \mu \mathrm{g} / \mathrm{mL}$ and $24.6 \pm 2.4 \mu \mathrm{g} / \mathrm{mL}$, respectively. $24.6 \pm 2.5 \mu \mathrm{g} / \mathrm{mL}$ and $35.6 \pm 7.4 \mu \mathrm{g} / \mathrm{mL}$ concentrations were detected in groups treated with dose of $20 \mathrm{mg} / \mathrm{kg}$ one or seven times, respectively. The results are summarized in Fig. 4.

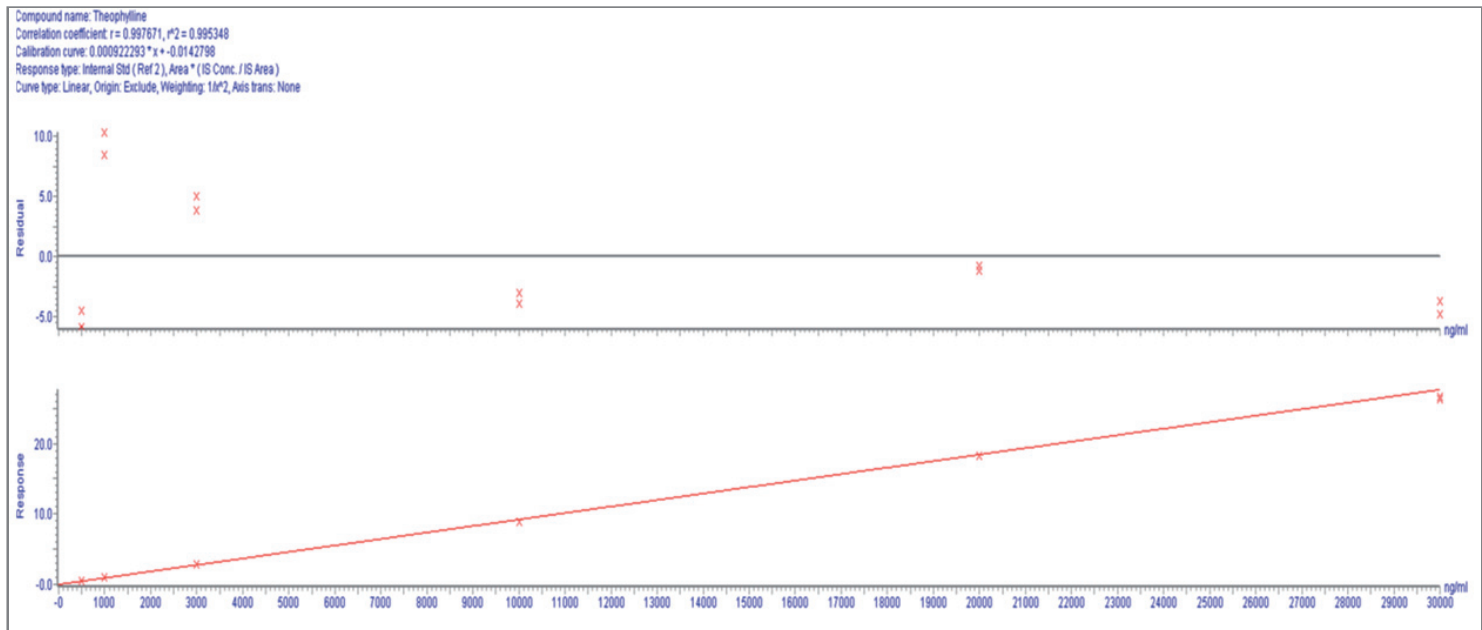

Fig. 3 Calibration curve for extracted theophylline from guinea pig plasma with calibration coefficient and calibration curve parameters. Plot of response factor (y-axis) versus concentration in $\mathrm{ng} / \mathrm{mL}$ ( $\mathrm{x}$-axis).

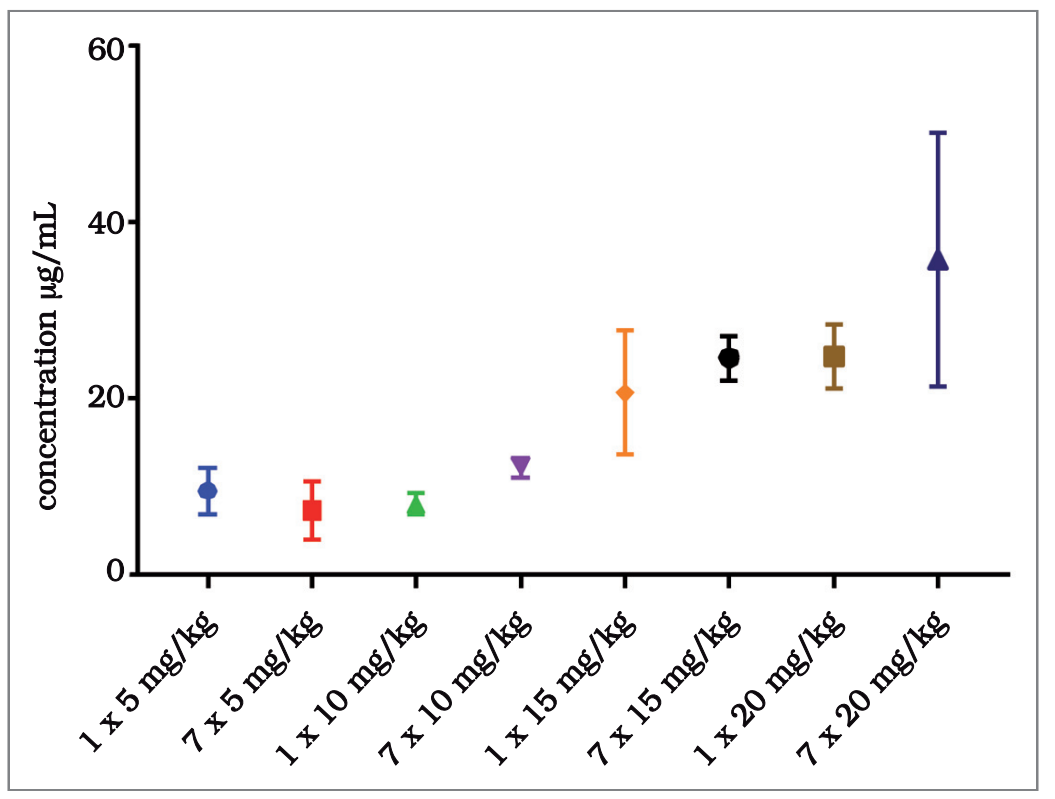

Fig. 4 Concentrations of theophylline in guinea pig plasma groups at different administrated doses single dose of repeated dose -7 days $(5 \mathrm{mg} / \mathrm{kg}, 10 \mathrm{mg} / \mathrm{kg}$, $15 \mathrm{mg} / \mathrm{kg}$, and $20 \mathrm{mg} / \mathrm{kg}$ ). Data are shown as mean \pm standard error of measurement. 
In our previous study (15) we compared the effects of theophylline on airway reactivity in in vivo and in vitro conditions, as well as its anti-inflammatory effects. The administration of various doses of theophylline led to suppressive effect on several markers of inflammation (relative eosinophil counts in bronchoalveolar lavage fluid and plasma, IL-4 and IL-5 concentrations in lung homogenate, suppressed airway reactivity), which correlated with measured plasma concentrations. However, in that study UPLC method with UV detector was used and the plasma levels obtained by that detection differed from concentrations measured in this study. Therefore, when considering the therapeutic range and the most suitable dosing regimen, the method for detection should be taken into account (6). The results presented in this study suggest that the dosing regimen of $10 \mathrm{mg} / \mathrm{kg}$ is fully in therapeutic range and $15 \mathrm{mg} / \mathrm{kg}$ was on the upper range with an increased risk of adverse effects. However, in this experiment we used guinea pigs and not humans; thus, the interspecies differences in pharmacokinetics should be considered and the results must be "translated" with caution. The measured plasma concentrations of theophylline in this experiment enable further evaluation of theophylline effects and their correlation with markers of inflammation, airway reactivity, cough responses, status of oxidation and apoptosis in the model of ovalbumin-induced allergic inflammation $(7,15,22)$.

\section{CONCLUSIONS}

In our study we developed and validated the UPLC-MS/MS method for determination of theophylline plasma concentrations in guinea pigs. The method was validated in compliance with EMA guidelines. For separation we used HILIC chromatography separation mode, which allowed us to reduce the time of sample preparation. The samples were prepared by protein precipitation without any purification step. The use of UPLC allows a rapid throughput with a 3.2-min run time. The method using a positive ion ionisation with MRM transitions is simple and demonstrated a good linearity over the analytical range from 0.5 to $30.0 \mu \mathrm{g} / \mathrm{mL}$. The relatively short sample preparation time, together with the short LC run time, make the present method practical for cost-effective, high-throughput sample analyses.

\section{REFERENCES}

1) Kanazawa H, Atsumi R, Matsushima Y, Kizu J. Determination of theophylline and its metabolites in biological samples by liquid chromatography-mass spectrometry. J Chromatogr A 2000, 870 (1-2): 87-96.

2) Tija JF, Colbert J, Back DJ. Theophylline metabolism in human liver microsomes: inhibiton studies. J Pharmacol Exp Ther 1996, 276 (3): 912-7.

3) Ha HR, Chen J, Freiburghaus AU, Follath F. Metablism of theophylline by cDNA-expressed human cytochromes P-450. Br J Clin Pharmacol 1995, 39 (3): 321-6.

4) Shukla D, Chakraborty S, Singh S, Mishra B. Doxofylline: A promising methylxanthine derivative for the treatment of asthma and chronic obstructive pulmonary disease. Expert Opin Pharmacother 2009, 10: 2343-56.

5) Rabe KF, Magnussen H, Dent G. Theophylline and selective PDE inhibitors as bronchodilators and smooth muscle relaxants. Eur Respir J 1995, 8: 637-42.

6) Barnes PJ. Theophylline: new perspectives for an old drug. Am J Respir Crit Care Med 2003, 167 (6): 813-8.

7) Mokry J, Nosalova G, Mokra D. Influence of xanthine derivatives on cough and airway reactivity in guinea pigs. J Physiol Pharmacol 2009, 60 (5): 87-91.

8) Weinberger M, Hendeles L. Theophylline in asthma. New Engl J Med 1996, 334 (21): 1380-8.

9) Kawai M, Kato M. Theophylline for the treatment of bronchial asthma: Present status. Method Find Exp Clin Pharmacol 2000, 22 (5): 309-20. 
10) Goseva Z, Gjorcev A, Kaeva BJ, Janeva EJ. Analysis of plasma concentrations of theophylline in smoking and non-smoking patients with asthma. Open Access Maced J Med Sci 2015, 3 (4): 672-5.

11) Barnes PJ. Theophylline. Am J Respir Crit Care Med 2013, 188 (8): 901-6.

12) Al-Jenoobi FI, Ahad A, Mahrous GM, Raish M, Alam MA, Al-Mohizea AM. A simple HPLC-UV method for the quantification of theophylline in rabbit plasma and its pharmacokinetic application. J Chromatorgr Sci 2015, 53 (10):1765-70.

13) Nirogi RV, Kandikere VN, Shukla M, Mudigonda K, Ajjala DR. A simple and rapid HPLC/UV method for the simultaneous quantification of theophylline and etofylline in human plasma. J Chromatogr B Analyt Technol Biomed Life Sci 2007, 848 (2): 271-6.

14) Kamberi M, Hajime N, Kamberi P, Uemura N, Nakamura K, Nakano S. Simultaneous determination of grepafloxacin, ciprofloxacin, and theophylline in human plasma and urine by HPLC. Ther Drug Monit 1999, 21 (3): 335-40.

15) Urbanova A, Kertys M, Simekova M, Mikolka P, Kosutova P, Mokra D, Mokry J. Bronchodilator and anti-inflammatory action of theophylline in model of ovalbumin-induced allergic inflammation. In: Pokorski M, editors. Pulmonary Infection and Inflammation. Advances in Experimental Medicine and Biology. vol 935. Springer; 2016. p. 53-62.

16) Charehasaz M, Gurbay A, Aydin A, Sahin G. Simple, fast and reliable liquid chromatographic and spectrophotometric methods for determination of theophylline in urine, saliva and plasma samples. Iran J Pharm Res 2014, 13 (2): 431-39.

17) Kertys M, Urbanova A, Medvedova I, Mokry J. LC-MS based metabolomics: A new insight into the diagnostics of known diseases. Interdiscip Toxicol 2017, 10 (2):31.

18) Chae J, Kim D, Lee B, Kim E, Kwon K. Development and validation of a sensitive LC-MS/MS method for the simultaneous quantitation of theophylline and its metabolites in rat plasma. J Chromatogr B Analyt Technol Biomed Life Sci 2012, 889-890: 44-9.

19) Buszewski B, Noga S. Hydrophilic interaction liquid chromatography (HILIC)-a powerful separation technique. Anal Bioanal Chem 2012, 402 (1): 231-47.

20) Nguyen HP, Schug KA. The advantages of ESI-MS detection in conjunction with HILIC mode separations: Fundamentals and applications. J Sep Sci 2008, 31 (9): 1465-80.

21) McCalley DV. Understanding and manipulating the separation in hydrophilic interaction liquid chromatography- a review. J Chromatogr A 2017, 1523: 49-71.

22) Heaton JC, McCalley DV. Some factors that can lead to poor peak shape in hydrophilic interaction chromatography, and possibilities for their remediation. J Chromatogr A 2016, 1427: 37-44.

23) Mokra D, Tonhajzerova I, Pistekova H, Visnovcova Z, Mokry J, Drgova A, Repcakova M, Calkovska A. Short-term cardiovascular effects of selective phosphodiesterase 3 inhibitor olprinone versus non-selective phosphodiesterase inhibitor aminophylline in a meconium-induced acute lung injury. J Physiol Pharmacol 2013, 64(6): 751-9.

24) Mokra D, Tonhajzerova I, Mokry J, Petraskova M, Hutko M, Calkovska A. Cardiovascular side effects of aminophylline in meconium-induced acute lung injury. Adv Exp Med Biol 2013, 756: 341-7.

25) Mokra D, Drgova A, Mokry J, Pullmann R, Redfors B, Petraskova M, Calkovska A. Comparison of the effects of low-dose vs. high-dose aminophylline on lung function in experimental meconium aspiration syndrome. J Physiol Pharmacol 2008, 59 Suppl 6:449-59.

26) EMA. Guideline on Bioanalytical Method Validation. 2012. Avaliable from: http://www.ema.europa.eu/docs/en_GB/document_library/Scientific_guideline/2011/08/WC500109686.pdf [cit. 2017-12-29].

27) Mokry J, Mokra D, Nosalova G, Beharkova M, Feherova Z. Influence of selective inhibitors of phospohodiesterase 3 and 4 on cough and airway reactivity. J Physiol Pharmacol 2009, 59: 473-82.

28) Matuszewski BK, Constanzer ML, Chavez-Eng CM. Strategies for the assessment of matrix effect in quantitative bioanalytical methods based on HPLC-MS/MS. Anal Chem 2003, 75: 3019-30.

29) Urbanova A, Medvedova I, Kertys M, Mikolka P, Kosutova P, Mokra D, Mokry J. Dose dependent effects of tadalafil and roflumilast on ovalbumin-induced airway hyperresponsiveness in guine pigs. Exp Lung Res 2017, 43 (9): 407-16. 
Acknowledgements: This work was supported by projects VEGA 1/0260/14, VEGA 1/0255/18, VEGA 1/0356/18, APVV-17-0052, by Grant UK/74/2017, and by the project „Biomedical Center Martin“, ITMS code: 26220220187, the project is co-financed from EU sources.

Received: October, 18, 2017

Accepted: October, 30, 2017 